Nigerian Journal of Environmental Sciences and Technology (NIJEST)

www.nijest.com

ISSN (Print): 2616-051X ｜ ISSN (electronic): 2616-0501

Vol 3, No. 1 March 2019, pp 18 - 29

\title{
An Assessment of the Reliability of the NIGNET Data
}

\author{
Ayodele E. G. ${ }^{1}$, Okolie C. J. ${ }^{2}{ }^{*}$ and Mayaki O. A. ${ }^{3}$ \\ ${ }^{1,2}$ Department of Surveying and Geoinformatics, Faculty of Enginering, University of Lagos, Lagos State, \\ Nigeria \\ ${ }^{3}$ Department of Geodesy and Geomatics Engineering, University of New Brunswick, Canada \\ Corresponding Author: *cokolie@unilag.edu.ng
}

\begin{abstract}
The Nigerian Geodetic Reference Frame is defined by a number of Continuously Operating Reference Stations (CORS) that constitute the Nigerian GNSS Network (NIGNET). NIGNET is essential for planning and national development with the main goal of ensuring consistency in the geodetic framework both nationally and internationally. Currently, the strength of the network in terms of data reliability has not been adequately studied due to the fact that research into CORS in Nigeria is just evolving, which constitutes a limitation in its applications. Therefore, the aim of this research is to explore the reliability of the 3-dimensional coordinates of NIGNET to inform usability and adequacy for both scientific and practical applications. In particular, this study examines if the 3-dimensional coordinates of NIGNET are equally reliable in terms of positional accuracy. Accordingly, this study utilised GNSS data collected over a period of six years (2011 2016) from the network to compute the daily geocentric coordinates of the stations. Exploratory and statistical data analysis techniques were used to understand the magnitude of the errors and the accuracy level in the 3-dimensional coordinates. For this purpose, accuracy metrics such as standard deviation $(\sigma)$, standard error (SE) and root mean square error (RMSE) were computed. While One-way ANOVA was conducted to explore the coordinate differences. The results obtained showed that SE and RMSE ranged from $13.00-56.50 \mathrm{~mm}$ and $14.38-73.16 \mathrm{~mm}$ respectively, which signifies high accuracy. Overall, while $88 \%$ of the network showed a high level of positional accuracy, the reliability has been compromised due to excessive gaps in the data archiving. Therefore, due attention must be given to NIGNET to achieve its purpose in the provision of accurate information for various geospatial applications. Also, any efforts directed at understanding the practical implications of NIGNET must be well-embraced for the realization of its set objectives.
\end{abstract}

Keywords: Geodetic Infrastructure, Reliability, NIGNET, CORS, Data Analysis

\subsection{Introduction}

Advancements in positioning have made Global Navigation Satellite Systems (GNSS) a critical component of the modern day geodetic infrastructure and services. In 2008, the Office of the Surveyor General of the Federation started the establishment of the Nigerian GNSS Reference Network (NIGNET). NIGNET consists of a network of Continuously Operating Reference Stations (CORS). Currently, NIGNET is formed by sixteen (16) CORS covering the entire country. CORS are a network of stations using GNSS operating continuously from permanent and stable locations for accurate positioning (Fajemirokun, 2009; Schwieger et al., 2009). CORS provide geodetic controls of comparable accuracy to the classical geodetic network and is a better alternative given the improvements in surveying and mapping technologies. CORS are categorised into different classes according to purpose and the spacing between stations. For example, Burns and Sarib (2010) and the Intergovernmental Committee on Survey and Mapping, ICSM (2014) classified CORS into Tiers 1-3 while LPI (2012) classified CORS into Tiers $1-5$. The use of CORS can give an instant position to an accuracy of $\pm 20 \mathrm{~mm}$ required by many industries (UNSW, 2017). 
For NIGNET, its main goal is to ensure consistency in the local (Nigerian Geodetic Reference Frame) with the International Terrestrial Reference Frame (ITRF). NIGNET serves as the fiducial network that defines the country's spatial reference framework as well as contributing to the African Geodetic Reference Frame (AFREF) using the techniques of modern space geodesy. The establishment of NIGNET is essential given that the national geodetic network of any country is a pivotal infrastructure that provides the foundation for all geo-related activities and services. Such services include land management, urban development, physical planning, construction, mineral exploration, and transportation (land, air and water). NIGNET also provides the base for a coherent multipurpose Land Information System and its subsequent maintenance. This is particularly useful in a country's economic development by delineating and monitoring changes in property, environment, and biodiversity. It is also vital in the smooth implementation of the national land policy (Jatau et al., 2010). In order to ensure consistency, the linking of NIGNET to the ITRF was made by acquiring Global Positioning System (GPS) data from nine International GNSS Service (IGS) stations (OSGOF, 2012). The IGS stations served as the reference points while the data used were acquired at the same time with the data from NIGNET.

Given the critical role played by NIGNET in defining the geocentric datum for Nigeria, it is important to account for any displacement arising from the shift in position of the CORS. Recently, Ayodele $e t$ al. (2017) analysed data from seven NIGNET stations covering 2011 to 2014 in order to monitor temporal variations and to understand the quality of the three-dimensional coordinates. The results showed an acceptable level in the data quality and accuracy of NIGNET with the highest and lowest variabilities in the initial coordinates occurring in the $x$ and $z$ directions respectively. The authors also noted some infrastructural problems plaguing NIGNET such as faulty receivers, irregular power supply, and disruptions in internet connectivity. The observations in the network led to the assessment of the accuracy in the three-dimensional coordinates of ten operational NIGNET stations from 20112016 using a known IGS station (BJCO) as reference. While the results from the study showed an acceptable level of accuracy, the reliability of the network remains unclear. Consequently, in this study, the reliability of the network was explored using both exploratory and quantitative analysis techniques such as the Mahalanobis distance method of outlier detection and filtering, standard deviation (S.D), standard error (S.E), mean absolute deviation (MAD) and root mean square error (RMSE) for accuracy metrics Also, analysis of variance (ANOVA) was used to test for any significant variation in the 3-dimensional coordinate to understand whether the $\mathrm{X}, \mathrm{Y}$, and $\mathrm{Z}$ coordinates are of different levels of reliability-. To conclude the reliability assessment, an evaluation of the sufficiency and adequacy of the NIGNET data was conducted using the data count of the daily observations in line with the IGS and ICSM guidelines for the acquisition of high quality CORS data.

\subsection{Materials and Methods}

Figure 1 presents the map of Nigeria showing the distribution of the NIGNET COR Stations used in this study. The downloaded files contained data from fourteen (14) NIGNET stations that were available on the online portal and two IGS stations (CGGN and BJCO). Following this, a custom MATLAB script was written to call the offline function of the GNSS Analysis and Positioning Software (GAPS) to read the RINEX files from the folder they were placed. GAPS is a Precise Point Positioning (PPP) application developed at the University of New Brunswick, Canada. Further details about GAPS and how it functions can be found in Leandro et al. (2010) and Urquhart et al. (2014). During the processing, the geocentric coordinates of the stations were computed and extracted at a sampling interval of 30 seconds and then averaged into daily coordinates. A full description of the methodology for the processing of the station coordinates using GAPS can be found in Ayodele et al. (2017). Table 1 presents the summary of BJCO (the reference station) showing the geodetic coordinates and years of observations considered. From the table, the least number of yearly observations recorded was in year 2012 (248) while the highest number of observations was recorded in year 2014 (362). For the 6-year period from 2011-2016 under study, a total number of 1,875 available data files were acquired for BJCO. Four NIGNET stations with excessively large data gaps were excluded leaving a final selection of ten NIGNET stations. The excluded stations include HUKP (Katsina), FPNO (Owerri), FUTA (Akure) and GEMB (Gembu). MDGR had severe service disruptions during this period making it the station with the least number of observations (369 data files) while FUTY had the highest number of observations (1799 data files). 


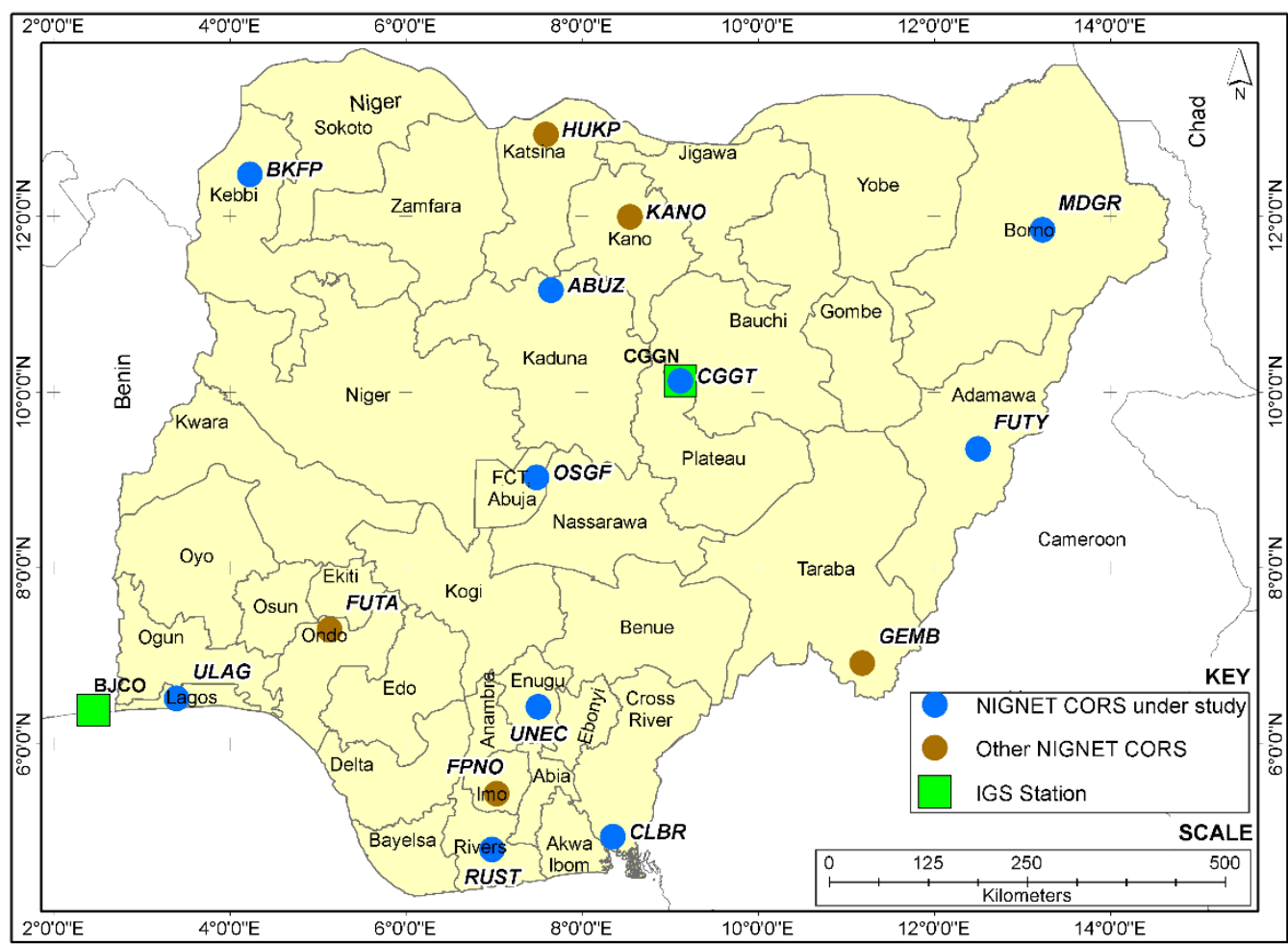

Figure 1: Map of Nigeria showing the distribution of the COR stations

Table 1: The description and the count of the downloaded daily data BJCO IGS station

\begin{tabular}{|l|l|l|l|l|l|l|l|l|l|l|}
\hline $\begin{array}{l}\text { Station } \\
\text { code }\end{array}$ & $\begin{array}{l}\text { Latitude } \\
\text { (degree) }\end{array}$ & $\begin{array}{l}\text { Longitude } \\
\text { (degree) }\end{array}$ & $\begin{array}{l}\text { Ellipsoidal } \\
\text { height }(\mathrm{m})\end{array}$ & Location & \multicolumn{4}{|c|}{ No. of Yearly Downloaded Observations (days) } \\
\cline { 7 - 12 } & BJCO & 6.38 & 2.45 & 30.7 & 2011 & 2012 & 2013 & 2014 & 2015 & $* 2016$ \\
\hline
\end{tabular}

*1 Jan - 10 Nov, 2016

Following the determination of the coordinates of the stations using GAPS, a final set of daily coordinates for the first months of observation were averaged to derive the initial coordinates for each station. The next stage of the data processing and analysis utilised $R$ (a language for computing and statistical analysis) to compute the Mahalanobis Distances. The data points beyond the Mahalanobis distance cut-off value were filtered out as outliers. To obtain a detailed picture of the magnitude of the errors and the accuracy level in the three-dimensional coordinates, the following accuracy metrics were computed: standard deviation - S.D $(\sigma)$, standard error - S.E $(\sigma / \sqrt{N})$, mean absolute deviation (MAD) and root mean square error (RMSE). Correlation analysis was also performed to check for the correlation between the coordinate differences in the three directions. The MAD and RMSE have been widely used by researchers to measure model performance and are calculated for the data as follows (Chai and Draxler, 2014):

$$
\begin{aligned}
& M A D=\frac{1}{n} \sum_{i=1}^{n}\left|e_{i}\right| \\
& R M S E=\sqrt{\frac{1}{n} \sum_{i=1}^{n} e_{i}^{2}}
\end{aligned}
$$

Next, using the Statistical Package for the Social Sciences (SPSS) version 16.0, an ANOVA test was conducted to explore the differences in the filtered $\mathrm{X}, \mathrm{Y}$ and $\mathrm{Z}$ - coordinate differences. The null hypothesis $\left(H_{0}\right)$ is that there is no significant difference in the means of the $\mathrm{X}, \mathrm{Y}$ and $\mathrm{Z}$ coordinate differences or that the 3-dimensional coordinates are equally reliable. The converse forms the alternative hypothesis $\left(H_{l}\right) . H_{0}$ is rejected if the $p$-value is less than the significance level of 0.05 . If $H_{0}$ is rejected, meaning there is a significant difference among the groups, then a Tukey post-hoc analysis will be conducted in order to determine which specific groups differed from each other. Finally, to evaluate the sufficiency and adequacy of the NIGNET data, the data count of daily observations from the NIGNET portal was compared with that of an IGS station (BJCO) which is 
believed to comply with the IGS and ICSM guidelines for the acquisition of high quality CORS data. One of the IGS requirements is the need to have long time series of continual stable measurements with as few disruptions and configuration changes as possible (IGS, 2017). For Tiers 1 and 2, less than $8 \mathrm{~min} /$ day and $9 \mathrm{hr} /$ year of data outage is recommended, while for Tier $3 \mathrm{CORS}$, data outage should be less than $15 \mathrm{~min} /$ day and $44 \mathrm{hr} /$ year (ICSM, 2014). ICSM (2014) also recommended a survey uncertainty of better than $20 \mathrm{~mm}$. These recommendations formed the basis for the assessment of the adequacy of the network data.

\subsection{Results}

\subsection{Exploratory data analysis}

Using the Mahalanobis distance method, the variability in the daily coordinates was analysed to screen out the outliers. Figure 2 shows a sample plot of X-coordinate differences against the Mahalanobis distance. All coordinate points beyond the cutoff distance of 2.795 were filtered off as outliers. This manifests in the density plot of the squared Mahalanobis distance shown in Figure 3. The good quality observations are concentrated towards the left portion of the plot. Further right, moving away from the square of the cut-off value, the outliers start to thin out over greater distances. Figure 4 shows a Q-Q plot of the squared Mahalanobis distance against the quantiles of chi-square of 2 degrees of freedom while Figure 5 presents a boxplot of the coordinate differences at all stations in the $\mathrm{x}$-direction.

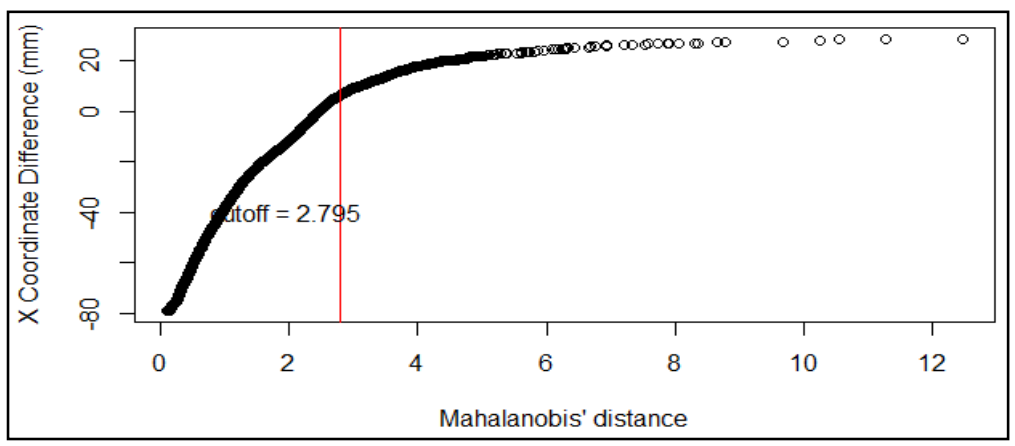

Figure 2: Plot of $x$-coordinate differences against the Mahalanobis distance

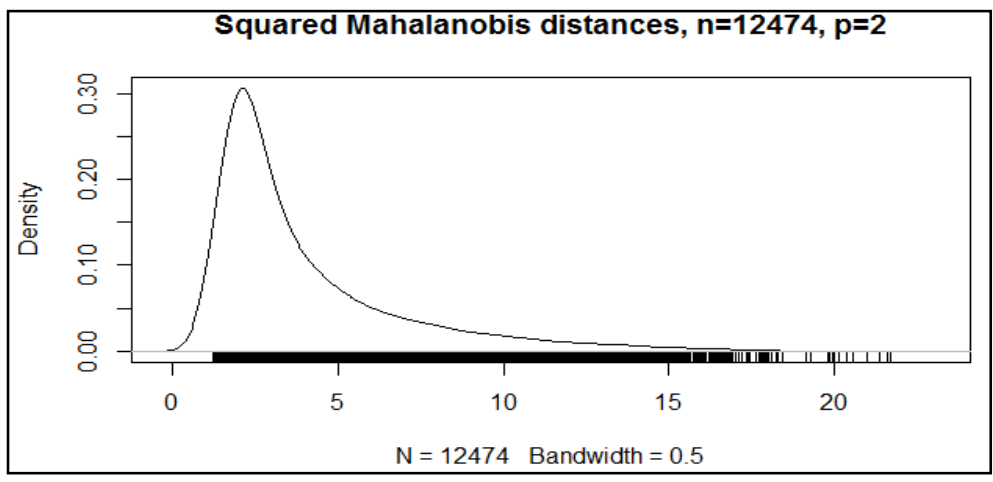

Figure 3: Density plot of squared Mahalanobis distance 


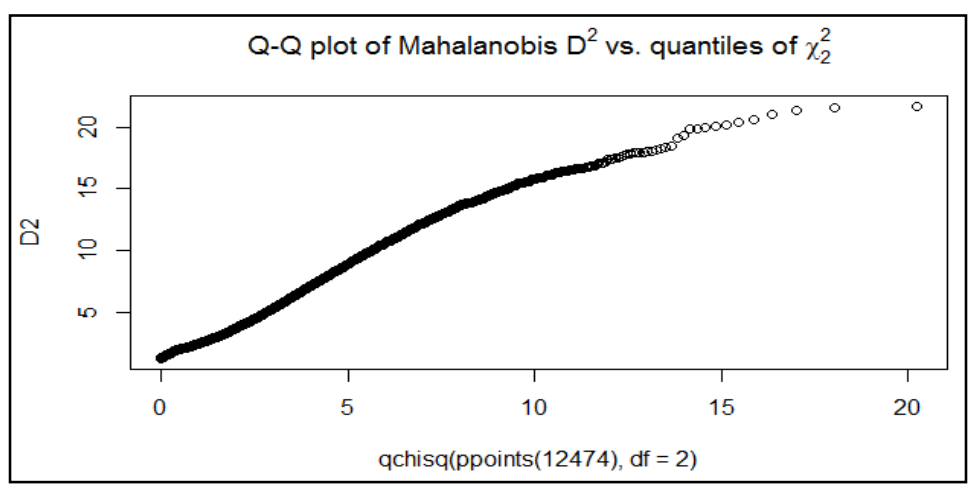

Figure 4: Q-Q plot of the squared Mahalanobis distance against the quantiles of chi-square of 2 degrees of freedom

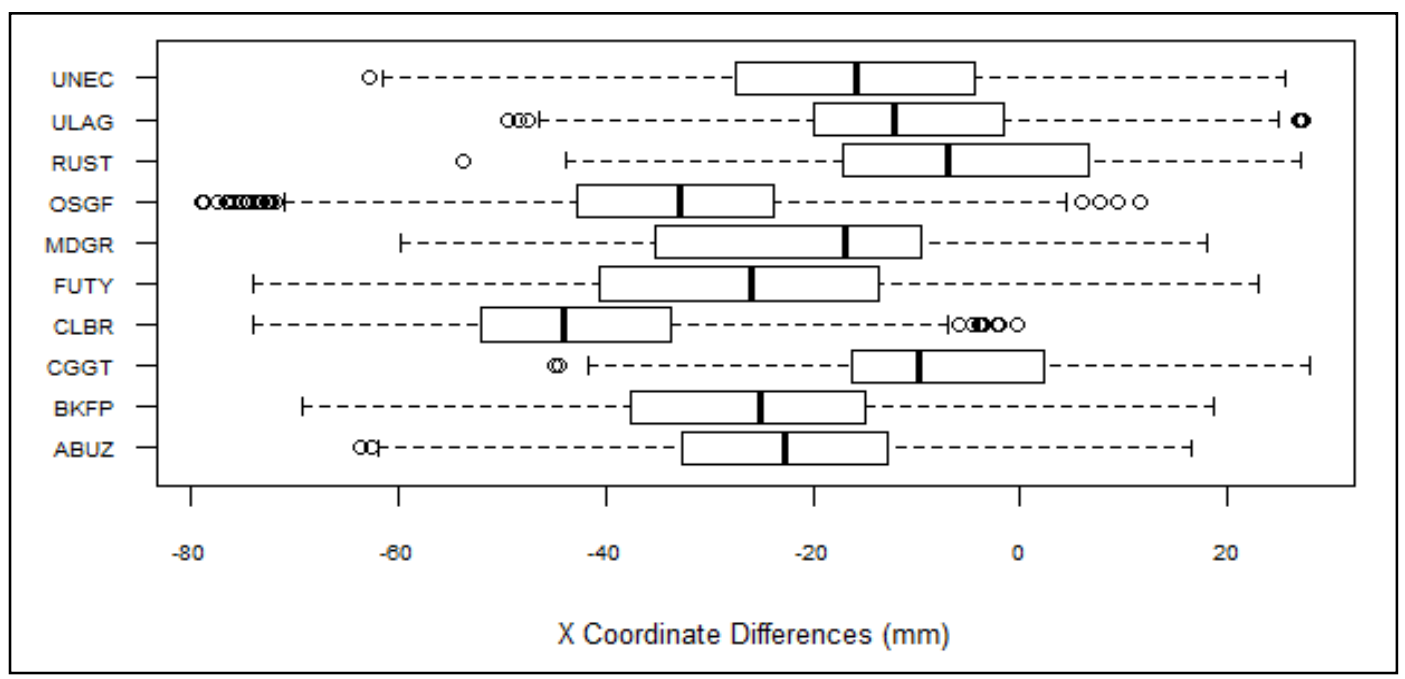

Figure 5: Boxplots of coordinate differences at all stations in the $x$-direction

\subsection{Quantitative data analysis}

\subsubsection{Analysis of the initial station coordinates}

Table 2 shows the mean and standard deviations of the initial station coordinates. The SDs in the $\mathrm{x}, \mathrm{y}$ and z-directions are denoted by $S D X_{i}, S D Y_{i}$ and $S D Z$ respectively. The results for the IGS station show that $\mathrm{BJCO}$ has SDs of $8.9 \mathrm{~mm}, 9.1 \mathrm{~mm}$ and $4.4 \mathrm{~mm}$ in the $\mathrm{x}, \mathrm{y}$ and $\mathrm{z}$ directions respectively. In a general assessment of all the eleven IGS and NIGNET stations to understand the level of variability in the initial coordinates, MDGR has the lowest SD $(4.9 \mathrm{~mm})$ while CLBR has the highest SD $(31.6 \mathrm{~mm})$ in the $\mathrm{x}$-direction. This signifies the stations with the minimum and maximum variability in the $\mathrm{x}$ coordinates. In the y-direction, ABUZ and BKFP are the least variable stations with an SD of $2.5 \mathrm{~mm}$ while OSGF presents the highest variability $(\mathrm{SD}=11.2 \mathrm{~mm}$ ). In the z-direction, CLBR and BJCO are the stations with the minimum and maximum variability in coordinates with SDs of $1.4 \mathrm{~mm}$ and 4.4 $\mathrm{mm}$. From the initial assessment, there is no clear indication of whether geographical location is responsible for the variability in coordinates. This is evidenced in the randomness observed in the distribution of the locations of the minimum and maximum values. 
Table 2: Mean and standard deviations (SDs) of the computed initial coordinates

\begin{tabular}{|l|l|l|l|l|l|l|l|}
\hline Station & $\overline{\boldsymbol{X}}_{\boldsymbol{i}}(\boldsymbol{m})$ & $\overline{\boldsymbol{Y}}_{\boldsymbol{i}}(\boldsymbol{m})$ & $\overline{\boldsymbol{Z}}_{\boldsymbol{i}}(\boldsymbol{m})$ & $\boldsymbol{S} \boldsymbol{D}_{\boldsymbol{X}_{\boldsymbol{i}}}(\boldsymbol{m})$ & $\boldsymbol{S D}_{\boldsymbol{Y}_{\boldsymbol{i}}}(\boldsymbol{m})$ & $\boldsymbol{S D}_{\boldsymbol{Z}_{\boldsymbol{i}}}(\boldsymbol{m})$ & $\mathbf{N}$ \\
\hline ABUZ & 6203493.826 & 833088.697 & 1225614.635 & 0.007 & 0.003 & 0.002 & 28 \\
\hline BJCO & 6333076.479 & 270973.572 & 704552.107 & 0.009 & 0.009 & 0.004 & 16 \\
\hline BKFP & 6211960.353 & 459365.476 & 1368115.049 & 0.006 & 0.003 & 0.002 & 29 \\
\hline CGGT & 6201032.284 & 995277.242 & 1113815.522 & 0.007 & 0.003 & 0.003 & 29 \\
\hline CLBR & 6287174.239 & 922979.461 & 546713.767 & 0.032 & 0.006 & 0.001 & 3 \\
\hline FUTY & 6145058.500 & 1362078.873 & 1029389.914 & 0.008 & 0.004 & 0.003 & 30 \\
\hline MDGR & 6080449.306 & 1418433.497 & 1299949.426 & 0.005 & 0.003 & 0.002 & 15 \\
\hline OSGF & 6246471.278 & 820848.736 & 994267.941 & 0.010 & 0.011 & 0.003 & 21 \\
\hline RUST & 6308859.048 & 772229.925 & 530354.458 & 0.012 & 0.004 & 0.004 & 14 \\
\hline ULAG & 6326097.300 & 375576.105 & 719131.690 & 0.008 & 0.004 & 0.003 & 30 \\
\hline UNEC & 6284298.307 & 827900.511 & 708988.588 & 0.011 & 0.003 & 0.002 & 28 \\
\hline
\end{tabular}

\subsubsection{Analysis of the daily station coordinates}

Table 3 presents the mean absolute deviation (MAD) and root mean square error (RMSE) in the daily station coordinates from 2011-2016. In the table, the MAD describes the average distance of each daily coordinate from the mean (initial) station coordinates shown in Table 2. Similarly, the magnitude of the RMSE provides a good measure of the level of spread of the residuals in the data. CGGT has the lowest variability in the three directions $\left(M A D_{X}=12.20 \mathrm{~mm}, R M S E_{X}=14.38 \mathrm{~mm}\right.$; $M A D_{Y}=16.14 \mathrm{~mm}, \quad R M S E_{Y}=18.44 \mathrm{~mm} ; \quad M A D_{Z}=12.72 \mathrm{~mm}, \quad R M S E_{Z}=14.42 \mathrm{~mm} . \quad$ This observation is as expected and it is not unconnected with the fact that CGGT is located in a solid location compared to the other stations. Similarly, CLBR which is located in the coastal zone has the highest variability in $\mathrm{x}$ and $\mathrm{z}$-directions as expected $\left(M A D_{X}=42.77 \mathrm{~mm}, R M S E_{X}=44.96 \mathrm{~mm}\right)$, and CLBR $\left(M A D_{Z}=62.23 \mathrm{~mm}, R M S E_{Z}=67.02 \mathrm{~mm}\right)$, while FUTY $\left(M A D_{Y}=64.87 \mathrm{~mm}, R M S E_{Y}=\right.$ $73.16 \mathrm{~mm}$ ) has the highest variability y-directions.

Table 3: Summary of MAD and RMSE of the daily station coordinates from 2011-2016

\begin{tabular}{|l|l|l|l|l|l|l|}
\hline Station & $\begin{array}{l}\boldsymbol{M A D}_{\boldsymbol{X}} \\
(\mathbf{m m})\end{array}$ & $\begin{array}{l}\boldsymbol{M A D}_{\boldsymbol{Y}} \\
(\mathbf{m m})\end{array}$ & $\begin{array}{l}\boldsymbol{M A D}_{\boldsymbol{Z}} \\
(\mathbf{m m})\end{array}$ & $\begin{array}{l}\boldsymbol{R M S E _ { X }} \\
(\mathbf{m m})\end{array}$ & $\begin{array}{l}\boldsymbol{R M S E _ { \boldsymbol { Y } }} \\
(\mathbf{m m})\end{array}$ & $\begin{array}{l}\boldsymbol{R M S E _ { Z }} \\
(\mathbf{m m})\end{array}$ \\
\hline ABUZ & 23.4859 & 55.1011 & 44.6664 & 27.1957 & 63.6742 & 53.4848 \\
\hline BKFP & 26.8498 & 61.5280 & 48.2706 & 30.9037 & 70.7931 & 57.4000 \\
\hline CGGT & 12.2014 & 16.1382 & 12.7178 & 14.3844 & 18.4408 & 14.4192 \\
\hline FUTY & 27.7770 & 64.8650 & 53.7864 & 32.3625 & 73.1647 & 62.3040 \\
\hline MDGR & 21.5268 & 29.0277 & 21.9808 & 26.0540 & 37.5886 & 34.0503 \\
\hline OSGF & 33.8218 & 45.8082 & 31.3158 & 37.1361 & 55.1622 & 41.5294 \\
\hline RUST & 13.8697 & 25.2174 & 18.8248 & 16.7598 & 29.7339 & 22.6099 \\
\hline ULAG & 14.6185 & 38.3836 & 28.9511 & 17.6079 & 42.5873 & 32.2187 \\
\hline UNEC & 19.1426 & 57.3797 & 45.7222 & 23.0469 & 67.2318 & 55.1066 \\
\hline
\end{tabular}

For a quick visualisation of the relationships in the coordinate differences, Figure 6 presents a correlation plots in the 3-dimensions across all the stations. The random spread of the points in the $\mathrm{XY}$ and $\mathrm{XZ}$ scatter plots shows there is negative correlation between the $\mathrm{X}$ and $\mathrm{Y}$ coordinate differences. There is also a negative correlation between the $\mathrm{X}$ and $\mathrm{Z}$ coordinate differences. However, the YZ plot shows a tight grouping of the coordinate differences in the $\mathrm{y}$ and z-directions. This shows that there is a high correlation between the $\mathrm{Y}$ and $\mathrm{Z}$ coordinate differences. 


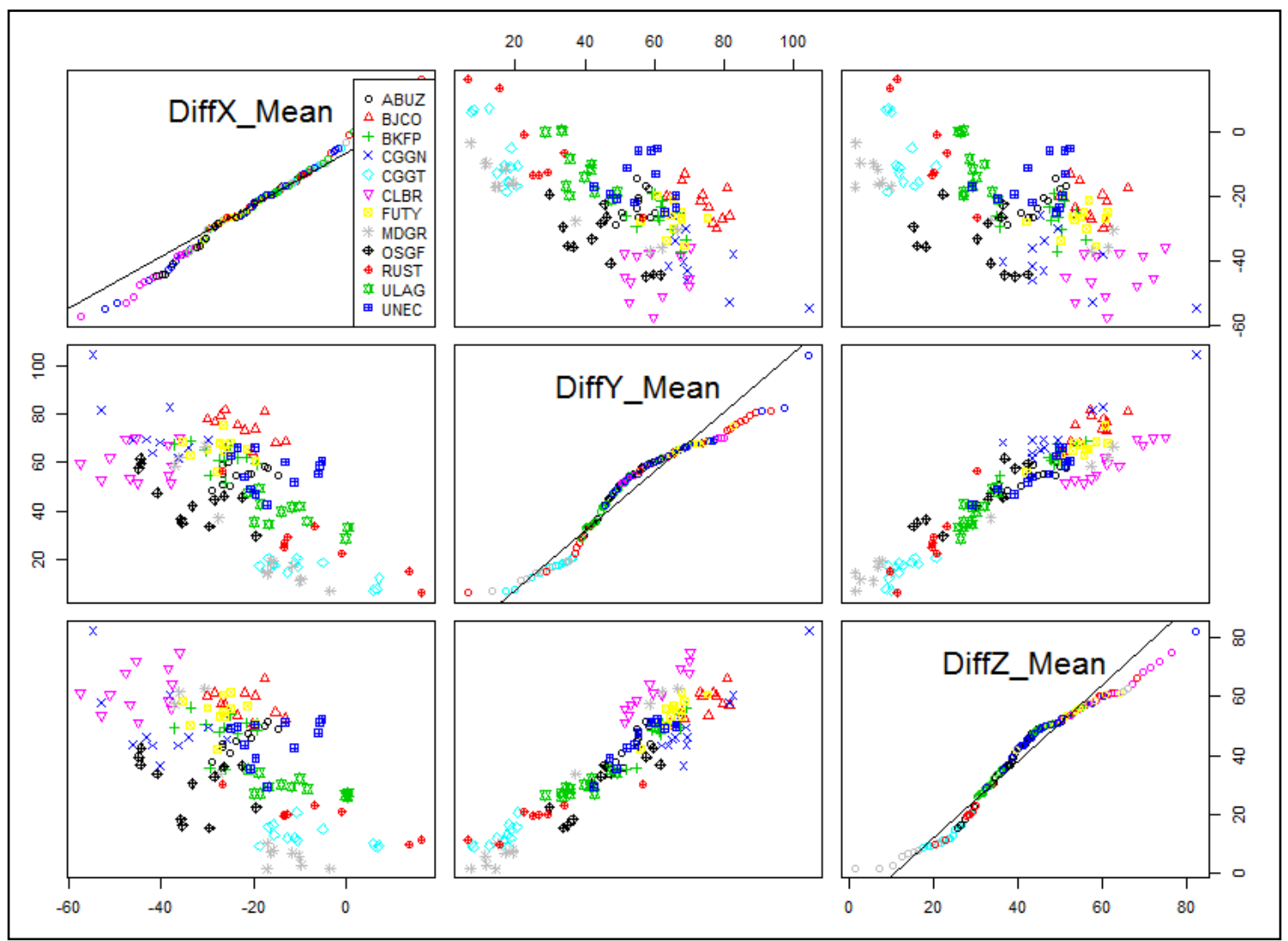

Figure 6: Correlation plot of the mean coordinate differences across all stations

3.2.3. Accuracy analysis of the yearly coordinate differences

After the outlier filtering using the Mahalanobis method, the descriptive statistics of the daily coordinate differences from 2011-2016 were calculated and are presented in Tables 4-6. For the coordinate differences in the x-direction, year 2015 has the least S.D of $12.839 \mathrm{~mm}$ while the highest S.D of $14.997 \mathrm{~mm}$ occurred in year 2013. For the y-direction, the least S.D was observed in the year $2011(9.125 \mathrm{~mm})$ while the highest S.D was observed in year $2013(13.200 \mathrm{~mm})$. The lowest and highest S.Ds in the Z-coordinate differences occurred in years $2016(5.038 \mathrm{~mm})$ and $2013(8.629$ $\mathrm{mm})$. Figure 7 presents a plot of the mean coordinate differences across all the stations from 20112016. From the figure, the result shows a strong relationship between the $Y$ and $Z$ coordinate differences as the dispersion of their differences from the initial coordinates follows the same trend and direction while the $X$ coordinate differences are moving in the opposite direction.

Table 4: Descriptive statistics of the mean X-coordinate differences from 2011-2016

\begin{tabular}{|c|c|c|c|c|c|c|c|c|}
\hline \multirow[t]{2}{*}{ Year } & \multirow[t]{2}{*}{$\mathrm{N}$} & \multirow{2}{*}{$\begin{array}{l}\text { Mean } \\
(\mathrm{mm})\end{array}$} & \multirow{2}{*}{$\begin{array}{l}\text { S.D } \\
(\mathrm{mm})\end{array}$} & \multirow{2}{*}{$\begin{array}{l}\text { S.E } \\
(\mathrm{mm})\end{array}$} & \multicolumn{2}{|c|}{ 95\% Confidence Interval for Mean (mm) } & \multirow{2}{*}{$\begin{array}{l}\text { Min } \\
(\mathrm{mm})\end{array}$} & \multirow{2}{*}{$\begin{array}{l}\text { Max } \\
(\mathrm{mm})\end{array}$} \\
\hline & & & & & Lower Bound & Upper Bound & & \\
\hline 2011 & 2438 & -8.585 & 13.539 & 27.400 & -9.122 & -8.047 & -55.80 & 28.00 \\
\hline 2012 & 2258 & -20.283 & 14.487 & 30.500 & -20.881 & -19.685 & -60.10 & 20.80 \\
\hline 2013 & 2082 & -24.231 & 14.997 & 32.900 & -24.876 & -23.587 & -68.90 & 23.70 \\
\hline 2014 & 1592 & -36.332 & 13.653 & 34.200 & -37.003 & -35.661 & -74.00 & 10.10 \\
\hline 2015 & 535 & -44.213 & 12.839 & 55.500 & -45.304 & -43.123 & -74.00 & -3.50 \\
\hline 2016 & 924 & -43.818 & 13.000 & 42.800 & -44.658 & -42.979 & -78.90 & -11.20 \\
\hline
\end{tabular}

Table 5: Descriptive statistics of the mean Y-coordinate differences from 2011-2016

\begin{tabular}{|c|c|c|c|c|c|c|c|c|}
\hline \multirow[t]{2}{*}{ Year } & \multirow[t]{2}{*}{$\mathrm{N}$} & \multirow{2}{*}{$\begin{array}{l}\text { Mean } \\
(\mathrm{mm})\end{array}$} & \multirow{2}{*}{$\begin{array}{l}\text { S.D } \\
(\mathrm{mm})\end{array}$} & \multirow{2}{*}{$\begin{array}{l}\text { S.E } \\
(\mathrm{mm})\end{array}$} & \multicolumn{2}{|c|}{$95 \%$ Confidence Interval for Mean (mm) } & \multirow{2}{*}{$\begin{array}{l}\text { Min } \\
(\mathrm{mm})\end{array}$} & \multirow{2}{*}{$\begin{array}{l}\text { Max } \\
(\mathrm{mm})\end{array}$} \\
\hline & & & & & Lower Bound & Upper Bound & & \\
\hline 2011 & 2438 & 16.893 & 9.125 & 18.500 & 16.531 & 17.256 & -26.20 & 83.30 \\
\hline 2012 & 2258 & 35.650 & 10.620 & 22.300 & 35.212 & 36.089 & -10.10 & 79.20 \\
\hline 2013 & 2082 & 58.548 & 13.200 & 28.900 & 57.981 & 59.116 & 9.00 & 108.80 \\
\hline 2014 & 1592 & 76.284 & 12.336 & 30.900 & 75.678 & 76.891 & 35.80 & 151.20 \\
\hline 2015 & 535 & 94.210 & 13.059 & 56.500 & 93.100 & 95.319 & 45.60 & 132.10 \\
\hline 2016 & 924 & 117.985 & 10.880 & 35.800 & 117.283 & 118.687 & 84.00 & 147.00 \\
\hline
\end{tabular}


Table 6: Descriptive statistics of the mean Z-coordinate differences from 2011-2016

\begin{tabular}{|c|c|c|c|c|c|c|c|c|}
\hline \multirow[t]{2}{*}{ Year } & \multirow[t]{2}{*}{$\mathrm{N}$} & \multirow{2}{*}{$\begin{array}{l}\text { Mean } \\
(\mathrm{mm})\end{array}$} & \multirow{2}{*}{$\begin{array}{l}\text { S.D } \\
(\mathrm{mm})\end{array}$} & \multirow{2}{*}{$\begin{array}{l}\text { S.E } \\
(\mathrm{mm})\end{array}$} & \multicolumn{2}{|c|}{ 95\% Confidence Interval for Mean (mm) } & \multirow{2}{*}{$\begin{array}{l}\text { Min } \\
(\mathrm{mm})\end{array}$} & \multirow{2}{*}{$\begin{array}{l}\operatorname{Max} \\
(\mathrm{mm})\end{array}$} \\
\hline & & & & & Lower Bound & Upper Bound & & \\
\hline 2011 & 2438 & 9.494 & 6.421 & 13.000 & 9.239 & 9.749 & -10.60 & 69.50 \\
\hline 2012 & 2258 & 26.855 & 7.564 & 15.900 & 26.542 & 27.167 & 0.50 & 54.30 \\
\hline 2013 & 2082 & 46.125 & 8.629 & 18.900 & 45.755 & 46.496 & 21.50 & 90.40 \\
\hline 2014 & 1592 & 65.750 & 6.689 & 16.800 & 65.421 & 66.079 & 43.70 & 112.40 \\
\hline 2015 & 535 & 85.972 & 7.044 & 30.500 & 85.374 & 86.570 & 65.60 & 106.30 \\
\hline 2016 & 924 & 104.269 & 5.038 & 16.600 & 103.943 & 104.594 & 88.00 & 122.30 \\
\hline
\end{tabular}

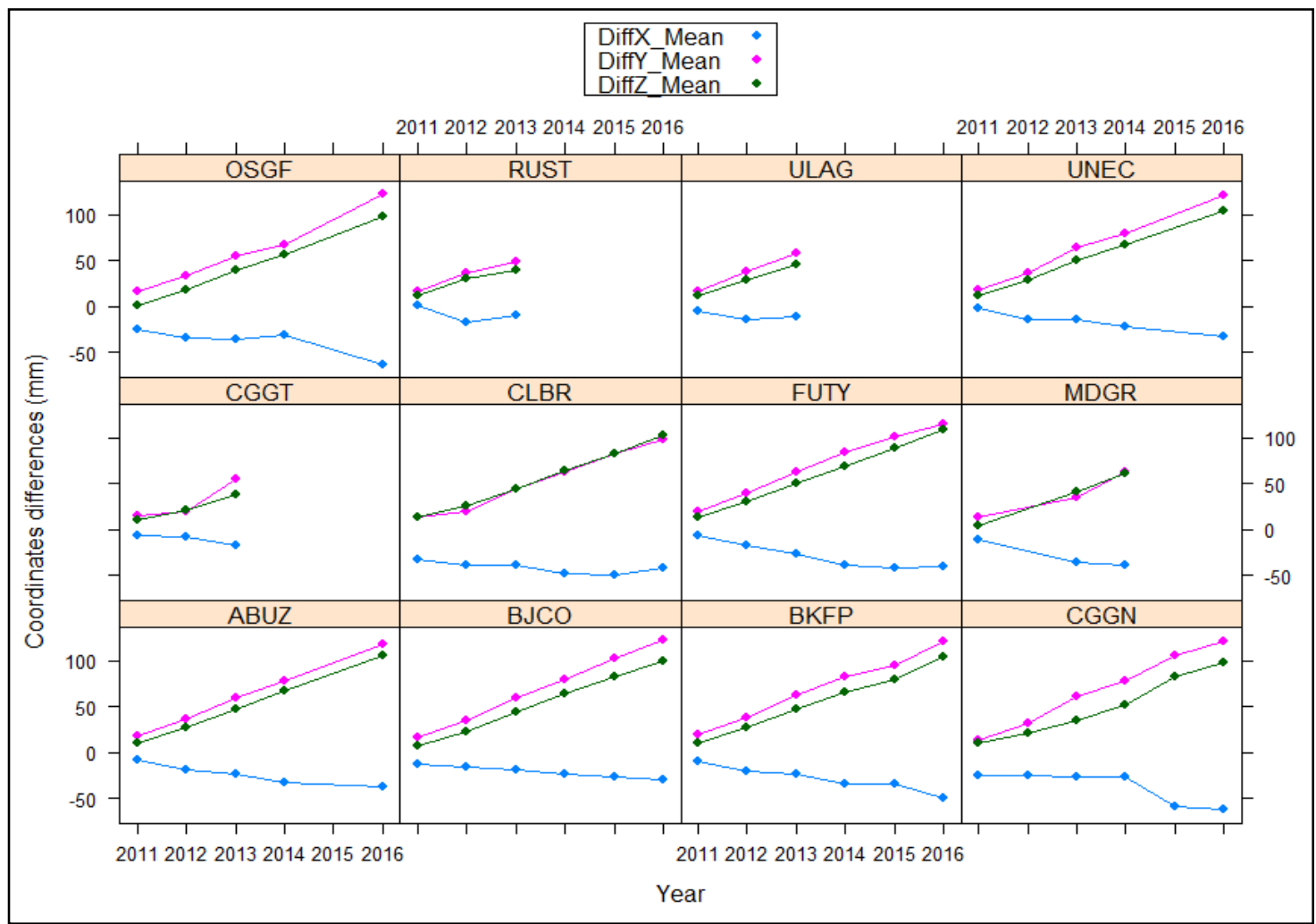

Figure 7: Mean coordinate differences across all stations from 2011 - 2016

In Figure 7, it is evident that the trend of dispersion of the $\mathrm{X}$-coordinate differences is significantly different from the $\mathrm{Y}$ and $\mathrm{Z}$ coordinate differences. Having established this fact, the next section presents an ANOVA test to analyse the periodic (yearly) variations in the $\mathrm{X}, \mathrm{Y}$ and $\mathrm{Z}$ coordinate differences.

\subsubsection{Analysis of variance in station coordinates}

The results of the ANOVA test in Table 7 shows that there is a significant difference between the $X$, $\mathrm{Y}$ and $\mathrm{Z}$ coordinate differences. The results of the ANOVA test suggest a rejection of the null hypothesis. Therefore, a Tukey Post-hoc test was conducted to further explore the differences in the epochs under comparison within the 2011-2016 period. The results of the Tukey Post-Hoc test presented in Tables 8-10 shows that there is a significant difference in the mean X-coordinate differences across all the epochs under study in the 2011-2016 period except for 2015 and 2016. That is, the mean X-coordinate differences for 2015 and 2016 are equally reliable. For the mean Ycoordinate differences and the mean Z-coordinate differences, there is a statistically significant difference between all the epochs under study in the 2011-2016 period.

The mean difference of the yearly comparisons shown in Table 8 yield the same value when viewed in both directions, the only difference being a change of sign from positive to negative or vice versa. For example, the mean difference for 2011-2012 is +11.698; for 2012-2011, it is -11.698. Consequently, the abridged versions of the post-hoc table are presented in Tables 8-10. 
Table 7: Results of ANOVA test

\begin{tabular}{|c|c|c|c|c|c|c|}
\hline & & Sum of Squares & $\mathrm{df}$ & Mean Square & $\mathrm{F}$ & Sig. \\
\hline \multirow[t]{3}{*}{ DiffX_Mean } & Between Groups & 1433173.256 & 5 & 286634.651 & 1460.00 & .000 \\
\hline & Within Groups & 1928973.462 & 9823 & 196.373 & & \\
\hline & Total & 3362146.717 & 9828 & & & \\
\hline \multirow[t]{3}{*}{ DiffY_Mean } & Between Groups & 9594701.173 & 5 & 1918940.235 & 14930.00 & .000 \\
\hline & Within Groups & 1262478.106 & 9823 & 128.523 & & \\
\hline & Total & 10860000.000 & 9828 & & & \\
\hline \multirow[t]{3}{*}{ DiffZ_Mean } & Between Groups & 8624702.076 & 5 & 1724940.415 & 33510.00 & .000 \\
\hline & Within Groups & 505669.629 & 9823 & 51.478 & & \\
\hline & Total & 9130371.705 & 9828 & & & \\
\hline
\end{tabular}

Table 8: Multiple comparisons of the mean X-coordinate differences with the Tukey Post-Hoc test

\begin{tabular}{|c|c|c|c|c|c|c|}
\hline \multirow[t]{2}{*}{ (I) Year } & \multirow[t]{2}{*}{ (J) Year } & \multirow{2}{*}{$\begin{array}{l}\text { Mean } \\
(\mathrm{mm})\end{array}$ Difference, $\quad \mathrm{I}-\mathrm{J}$} & \multirow{2}{*}{$\begin{array}{l}\text { S.E } \\
(\mathrm{mm})\end{array}$} & \multirow[t]{2}{*}{ Sig. } & \multicolumn{2}{|c|}{$95 \%$ Confidence Interval } \\
\hline & & & & & Lower Bound (mm) & Upper Bound (mm) \\
\hline \multirow[t]{5}{*}{2011} & 2012 & 11.698 & 0.409 & 0.000 & 10.532 & 12.865 \\
\hline & 2013 & 15.646 & 0.418 & 0.000 & 14.455 & 16.838 \\
\hline & 2014 & 27.747 & 0.452 & 0.000 & 26.46 & 29.034 \\
\hline & 2015 & 35.628 & 0.669 & 0.000 & 33.721 & 37.535 \\
\hline & 2016 & 35.234 & 0.541 & 0.000 & 33.691 & 36.777 \\
\hline \multirow[t]{4}{*}{2012} & 2013 & 3.948 & 0.426 & 0.000 & 2.734 & 5.162 \\
\hline & 2014 & 16.049 & 0.459 & 0.000 & 14.742 & 17.356 \\
\hline & 2015 & 23.93 & 0.674 & 0.000 & 22.009 & 25.85 \\
\hline & 2016 & 23.535 & 0.547 & 0.000 & 21.975 & 25.095 \\
\hline \multirow[t]{3}{*}{2013} & 2014 & 12.101 & 0.467 & 0.000 & 10.771 & 13.431 \\
\hline & 2015 & 19.982 & 0.679 & 0.000 & 18.046 & 21.918 \\
\hline & 2016 & 19.587 & 0.554 & 0.000 & 18.008 & 21.166 \\
\hline \multirow[t]{2}{*}{2014} & 2015 & 7.881 & 0.7 & 0.000 & 5.885 & 9.877 \\
\hline & 2016 & 7.486 & 0.58 & 0.000 & 5.834 & 9.138 \\
\hline 2015 & 2016 & -0.395 & 0.761 & 0.995 & -2.565 & 1.775 \\
\hline
\end{tabular}

Table 9: Multiple comparisons of the mean Y-coordinate differences with the Tukey Post-Hoc test

\begin{tabular}{|c|c|c|c|c|c|c|}
\hline \multirow[t]{2}{*}{ (I) Year } & \multirow[t]{2}{*}{ (J) Year } & \multirow{2}{*}{$\begin{array}{lll}\text { Mean } & \text { Difference, } & \text { I-J } \\
(\mathrm{mm}) & \end{array}$} & \multirow{2}{*}{$\begin{array}{l}\text { S.E } \\
(\mathrm{mm})\end{array}$} & \multirow[t]{2}{*}{ Sig. } & \multicolumn{2}{|c|}{ 95\% Confidence Interval } \\
\hline & & & & & Lower Bound (mm) & Upper Bound (mm) \\
\hline \multirow[t]{5}{*}{2011} & 2012 & -18.757 & 0.331 & 0.000 & -19.701 & -17.814 \\
\hline & 2013 & -41.655 & 0.338 & 0.000 & -42.619 & -40.691 \\
\hline & 2014 & -59.391 & 0.365 & 0.000 & -60.432 & -58.350 \\
\hline & 2015 & -77.316 & 0.541 & 0.000 & -78.859 & -75.774 \\
\hline & 2016 & -101.092 & 0.438 & 0.000 & -102.340 & -99.843 \\
\hline \multirow[t]{4}{*}{2012} & 2013 & -22.898 & 0.344 & 0.000 & -23.880 & -21.916 \\
\hline & 2014 & -40.634 & 0.371 & 0.000 & -41.691 & -39.576 \\
\hline & 2015 & -58.559 & 0.545 & 0.000 & -60.113 & -57.005 \\
\hline & 2016 & -82.334 & 0.443 & 0.000 & -83.596 & -81.073 \\
\hline \multirow[t]{3}{*}{2013} & 2014 & -17.736 & 0.377 & 0.000 & -18.812 & -16.660 \\
\hline & 2015 & -35.661 & 0.550 & 0.000 & -37.228 & -34.095 \\
\hline & 2016 & -59.437 & 0.448 & 0.000 & -60.714 & -58.159 \\
\hline \multirow[t]{2}{*}{2014} & 2015 & -17.925 & 0.567 & 0.000 & -19.540 & -16.310 \\
\hline & 2016 & -41.701 & 0.469 & 0.000 & -43.037 & -40.364 \\
\hline 2015 & 2016 & -23.775 & 0.616 & 0.000 & -25.531 & -22.020 \\
\hline
\end{tabular}

Dependent Variable - DiffY_Mean 
Table 10: Multiple comparisons of the mean Z-coordinate differences with the Tukey Post-Hoc test

\begin{tabular}{|l|l|l|l|l|l|l|}
\hline (I) Year & $(J)$ Year & $\begin{array}{l}\text { Mean Difference, I-J } \\
(\mathrm{mm})\end{array}$ & $\begin{array}{l}\text { S.E } \\
(\mathrm{mm})\end{array}$ & & Sig. & \multicolumn{3}{|c|}{ 95\% Confidence Interval } \\
\cline { 5 - 7 } & & -17.361 & 0.210 & 0.000 & -17.958 & -16.764 \\
\hline 2011 & 2012 & -36.632 & 0.214 & 0.000 & -37.242 & -36.022 \\
\hline & 2013 & -56.256 & 0.231 & 0.000 & -56.915 & -55.597 \\
\hline & 2014 & -76.479 & 0.343 & 0.000 & -77.455 & -75.502 \\
\hline & 2015 & -94.775 & 0.277 & 0.000 & -95.565 & -93.985 \\
\hline & 2016 & -19.271 & 0.218 & 0.000 & -19.892 & -18.649 \\
\hline 2012 & 2013 & -38.896 & 0.235 & 0.000 & -39.565 & -38.226 \\
\hline & 2014 & -59.118 & 0.345 & 0.000 & -60.101 & -58.134 \\
\hline & 2015 & -77.414 & 0.280 & 0.000 & -78.213 & -76.615 \\
\hline & 2016 & -19.625 & 0.239 & 0.000 & -20.306 & -18.944 \\
\hline 2013 & 2014 & -39.847 & 0.348 & 0.000 & -40.838 & -38.855 \\
\hline & 2015 & -58.143 & 0.284 & 0.000 & -58.952 & -57.335 \\
\hline & 2016 & -20.222 & 0.359 & 0.000 & -21.244 & -19.200 \\
\hline 2014 & 2015 & -38.519 & 0.297 & 0.000 & -39.364 & -37.673 \\
\hline & 2016 & -18.296 & 0.390 & 0.000 & -19.407 & -17.185 \\
\hline 2015 & 2016 & & & & \\
\hline
\end{tabular}

Dependent Variable - DiffZ_Mean

\subsection{Sufficiency and adequacy of the station coordinates}

Going further on the performance evaluation, the stations are expected to have a long time series of continuous stable measurements with as few disruptions as possible. Table 11 shows the NIGNET stations and the data count of daily observations available on the NIGNET server. In the period under study, the following stations had no data available on the NIGNET server - ABUZ (2015), CGGT (2014-2016), MDGR (2012; 2015-2016), OSGF (2015), RUST (2015-2016) and UNEC (2015-2016). It is observed that the data completeness has degraded overtime since the inception of NIGNET. The most severe cases of incomplete data occur in 2015 and 2016. Apparently, some components of the NIGNET infrastructure have been degrading with time and OSGOF has not been able to meet up with the maintenance demands.

Table 11: The selected NIGNET stations and the data count of daily observations

\begin{tabular}{|l|l|l|l|l|l|l|l|l|l|l|}
\hline $\begin{array}{l}\text { Station } \\
\text { code }\end{array}$ & $\begin{array}{l}\text { Latitude } \\
(\text { degree })\end{array}$ & $\begin{array}{l}\text { Longitude } \\
(\text { degree })\end{array}$ & $\begin{array}{l}\text { Ellipsoidal } \\
\text { height }(\mathrm{m})\end{array}$ & Location & \multicolumn{5}{|c|}{ No. of Observations (Days) } \\
\hline ABUZ & 11.15 & 7.65 & 706.1 & Zaria & 3611 & 2012 & 2013 & 2014 & 2015 & $* 2016$ \\
\hline BKFP & 12.47 & 4.23 & 251.0 & Birnin Kebbi & 365 & 366 & 355 & 350 & 0 & 180 \\
\hline CGGT & 10.12 & 9.12 & 917.4 & Toro & 365 & 39 & 116 & 0 & 0 & 0 \\
\hline CLBR & 4.95 & 8.35 & 61.5 & Calabar & 36 & 363 & 340 & 355 & 284 & 190 \\
\hline FUTY & 9.35 & 12.50 & 248.4 & Yola & 361 & 330 & 361 & 289 & 290 & 168 \\
\hline MDGR & 11.84 & 13.23 & 351.8 & Maiduguri & 262 & 0 & 11 & 96 & 0 & 0 \\
\hline OSGF & 9.03 & 7.49 & 533.6 & Abuja & 299 & 363 & 335 & 94 & 0 & 105 \\
\hline RUST & 4.80 & 6.98 & 46.6 & Port Harcourt & 304 & 132 & 52 & 84 & 0 & 0 \\
\hline ULAG & 6.52 & 3.40 & 45.5 & Lagos & 301 & 364 & 364 & 349 & 0 & 0 \\
\hline UNEC & 6.42 & 7.50 & 255.4 & Enugu & 362 & 366 & 364 & 365 & 54 & 216 \\
\hline
\end{tabular}

*1 Jan - 10 Nov, 2016

There were also cases of unprocessed observations. These unprocessed observations were due to the fact that some of the RINEX files downloaded from the NIGNET portal contained only single frequency data. The reason for this issue with the RINEX files might be attributed to receiver malfunctions, poor station maintenance or issues with data collection and handling. It is also possible that there were configuration issues in some of the RINEX files created by OSGOF. Within the period under study, the total number of NIGNET data files successfully processed ranged from $76.2 \%$ in 2014 to $99.3 \%$ in 2016 . However, virtually all the data files from BJCO were successfully processed with the least being $97.2 \%$ in 2012 as presented in Table 1 . The most severe cases of unprocessed data in NIGNET occurred in 2012 and 2014 at RUST - 319 unprocessed files (64.4\%) and 366 unprocessed files (100\%) respectively; at ULAG in 2014 - 364 unprocessed files $(99.7 \%)$ and at UNEC in 2015 - 365 unprocessed files (100\%). Other significant cases occurred at CLBR - 2012 (19.6\%), RUST - 2011 (29.9\%), ULAG - 2013 (19.0\%) and UNEC - 2014 (34.2\%). Despite the observed disruptions in the data from BJCO, the IGS data are still more consistent and well distributed over the period under consideration. At no point was BJCO offline all year round as in the case of some NIGNET stations. This points to the fact that the IGS stations are well monitored and 
better maintained than NIGNET. Summarily, the analysis conducted revealed a gross deficiency in data archiving and a consequent inadequacy of the network data to meet with the various geodetic needs. This is particularly evident in 2015 with maximum of $77 \%$ and $81 \%$ data recording in only two stations (CLBR and FUTY). The condition is worse in 2016 as only one station (BKFP) recorded up to $60 \%$ data.

\subsection{Conclusion}

This study examined the reliability of the GNSS data collected over a period of six years (2011 2016) from the Nigerian CORS network (NIGNET). Both exploratory and statistical data analysis techniques were used in the study to arrive at a concrete conclusion. The results obtained showed that while more than $80 \%$ of the network data is highly accurate in terms of positional accuracy and stability, the adequacy is highly deficient. This constitutes a serious challenge considering the requirements to meet various geodetic and geospatial needs. The current results revealed a $100 \%$ substandard in data recording and archiving in 2015 and 2016 when compared with the IGS standard. The trend observed in the data showed a deteriorating state that if nothing is done to address it, then not only is its objectives cannot be realised but also its sustainability is not guaranteed. To avoid this, the relevant stakeholders are enjoined to work together to salvage the network from failure.

\section{Acknowledgements}

The authors are grateful to the Office of the Surveyor General of the Federation (OSGOF), Nigeria and to the International GNSS Service (IGS) for the access granted to the NIGNET and IGS network data respectively. The authors also thank the Department of Geodesy and Geomatics Engineering, University of New Brunswick, Canada for the access to the offline version of GAPS for batch processing of the CORS data. Other relevant contributors are also appreciated.

\section{References}

Ayodele, E.G., Okolie, C.J., Ezeigbo, C.U. and Fajemirokun, F.A. (2017). Evaluation of Continuously Operating Stations (CORS) Data for the Definition of Nigerian Geodetic Reference Frame. Paper presented at the Nigerian Association of Geodesy General Assembly/Conference, Port-Harcourt.

Burns, D. and Sarib, R. (2010). Standards and Practices for GNSS CORS Infrastructure, Networks, Techniques and Applications. FIG Congress 2010. Sydney, Australia, 11-16 April 2010.

Chai, T. and Draxler, R.R. (2014). Root mean square error (RMSE) or mean absolute error (MAE)? Arguments against avoiding RMSE in the literature. Manuscript prepared for Geosci. Model Dev. Discuss. with version 4.1 of the LATEX class copernicus discussions.cls. Date: 1 May 2014

Fajemirokun, F.A. (2009). Benefits of GNSS/AFREF NIGNET Project. Presented at the International Awareness Conference on CORS using GNSS, Abuja 2009.

ICSM (2014). Guideline for Continuously Operating Reference Stations Special Publication 1, Version 2.1. Intergovernmental Committee on Surveying and Mapping (ICSM) - Permanent Committee on Geodesy

IGS (2017). Site Guidelines Clarifications. Retrieved from the International GNSS Service, IGS website. https://kb.igs.org/hc/en-us/articles/203840328/ (Date accessed - 30 Aug, 2017).

Jatau, B., Edozie, U., Fernandes, R., Adebomehin, A. \& Goncalves, N. (2010). NIGNET - The New Permanent GNSS Network of Nigeria. FIG 2010 - Sydney, Australia - 13 April 2010.

Leandro, R.F., Santos, M.C. and Langley, R.B. (2010). Analysing GNSS data in Precise Point Positioning Software. GPS Solutions, doi: 10.1007/s10291-010-0173-9

LPI (2012). Guidelines for CORSnet-NSW Continuously Operating Reference Stations (CORS), version 1.1. NSW Government - Land and Property Information. 
OSGOF (2012). Report on NIGNET GNSS Data Processing 2010 - 2011.

Schwieger, V., Lilje, M. and Sarib, R. (2009). GNSS CORS - Reference Frames and Services. International Federation of Surveyors (FIG), Article of the Month - December 2009.

UNSW (2017). What is a CORS Network? The University of New South Wales website. http://www.sage.unsw.edu.au/currentstudents/ug/projects/Gowans/Thesis/What_is_it.html/ (Date accessed - 28 Aug, 2017)

Urquhart, L., Santos, M.C., Garcia, C.A., Langley, R.B. and Leandro, R.F. (2014). Global Assessment of UNB's Online Precise Point Positioning Software. IAG Symposia Series, 139: 585-592, doi:10.1007/978-3-642-37222-3_77. 